\title{
Analisis Faktor Bauran Pemasaran Terhadap Keputusan Pembelian Minuman Kopi Banaran 9 di Coffe and Tea Colomadu
}

\author{
Ima Yunita Indriyanti ${ }^{{ }^{*}}$,Heru Irianto ${ }^{2}$, Mei Tri Sundari ${ }^{3}$ \\ ${ }^{1}$ Program Studi Agribisnis Fakultas Pertanian Universitas Sebelas Maret \\ ${ }^{2}$ Program Studi Agribisnis Fakultas Pertanian Universitas Sebelas Maret \\ ${ }^{3}$ Program Studi Agribisnis Fakultas Pertanian Universitas Sebelas Maret \\ Email korespondensi : imayunita20@gmail.com
}

\begin{abstract}
This study aims to determine the factors of marketing mix considered by consumers and the most considered variable in the purchase of drink coffee at Banaran 9 Coffee and Tea, Colomadu, Karanganyar Regency. The variables used in this study consisted of 22 variables. The basic method of this research is descriptive and analytical. Determination of location is done by purposive. The sampling method is purposive sampling and total samples is five times the number of variables. This study takes a sample of 110 people. The analytical method used is factor analysis. The results of the factor analysis research show that there are 22 variables and are covered by seven main factors that make up the purchase decision. These factors based on their priorities are product factors 24,042\%; promotion factor 10.507\%; process factors 9,913; person factor $8.845 \%$; physical evidence factor $5.815 \%$; place factor $5,815 \%$ and price factor $4,916 \%$. While the variable that is most considered by looking at the highest factor loading value is the taste variable with a factor loading value of 0.929 .
\end{abstract}

Keywords: Factor Analysis, Marketing Mix, Factor Loading, Coffee Shop, Buying Decision, Coffee

\section{INTISARI}

Penelitian ini bertujuan untuk mengetahui faktor-faktor bauran pemasaran yang dipertimbangkan konsumen serta variabel yang paling dipertimbangkan dalam pembelian produk minuman kopi pada Banaran 9 Coffee and Tea Colomadu, Kabupaten Karanganyar. Variabel yang digunakan dalam penelitian ini terdiri dari 22 variabel. Metode dasar penelitian ini adalah deskriptif dan analitis. Penentuan lokasi dilakukan secara purposive. Metode pengambilan sampel adalah purposive sampling dan jumlah sampel ditetapkan lima kali jumlah variabel. Dengan demikian, penelitian ini mengambil sampel yang digunakan sebanyak 110 orang Metode analisis yang digunakan adalah analisis faktor. Hasil penelitian analisis faktor menunjukkan bahwa terdapat 22 variabel dan tercakup dalam tujuh faktor utama yang membentuk keputusan pembelian. Faktor tersebut berdasarkan prioritasnya adalah faktor produk 24,042\%; faktor promosi 10,507\%; faktor proses 9,913 ; faktor orang $8,845 \%$; faktor bukti fisik $5,815 \%$; faktor tempat $5,815 \%$ dan faktor harga $4,916 \%$. Sedangkan variabel yang paling dipertimbangkan dengan melihat nilai factor loading tertinggi yaitu variabel rasa dengan nilai factor loading 0,929.

Kata kunci: Analisis Faktor, Bauran Pemasaran, Factor Loading, Kedai Kopi, Keputusan Pembelian, Kopi

\section{PENDAHULUAN}

Kopi adalah salah satu dari beberapa komoditas unggulan untuk dikembangkan pada sektor agribisnis. Kopi juga merupakan sumber mata pencaharian lebih dari satu setengah juta petani di Indonesia (Rahardjo dalam Praza, 2017). Perkembangan produksi kopi di Indonesia terbesar ke empat di dunia setelah Brazil, Vietnam, dan Kolombia. Tingkat produksi kopi yang tinggi, selain menjadi sumber penghasilan petani, tetapi juga sebagai sumber pendapatan devisa negara. Jumlah ekspor kopi di Indonesia menurut International Coffee Organization (ICO) ekspor kopi Indonesia terbesar kedua setelah brazil dari lima besar konsumsi kopi di dunia. Hal ini menunjukkan bahwa jumlah ekspor kopi di Indonesia meningkat dari tahun ke tahun. 
ISSN : 2622-6154 (print)

Tabel 1. Negara Ekspor Kopi Terbesar di Dunia (Bags @60kg) Tahun 2014-2018

\begin{tabular}{lccccc}
\hline Negara & $2014 / 15$ & $2015 / 16$ & $2016 / 17$ & $2017 / 18$ & CAGR \\
\hline Brazil & 20.333 .000 & 20.508 .000 & 21.225 .000 & 21.997 .000 & $2,7 \%$ \\
Indonesia & $\mathbf{4 . 4 1 7 . 0 0 0}$ & $\mathbf{4 . 5 5 5 . 0 0 0}$ & $\mathbf{4 . 6 5 0 . 0 0 0}$ & $\mathbf{4 . 7 0 0 . 0 0 0}$ & $\mathbf{2 , 1 \%}$ \\
Ethiophia & 3.625 .000 & 3.700 .000 & 3.725 .000 & 3.750 .000 & $1,1 \%$ \\
Filipina & 2.800 .000 & 3.000 .000 & 3.000 .000 & 3.000 .000 & $2,3 \%$ \\
Mexico & 2.347 .000 & 2.329 .000 & 2.360 .000 & 2.400 .000 & $0,7 \%$ \\
\hline
\end{tabular}

Sumber : International Coffee Organization, 2017

Tabel 1 diketahui bahwa ekspor kopi di Indonesia mengalami kenaikan setiap tahunnya. Laju Pertumbuhan Majemuk Tahunan atau Compound Annual Growth Rate (CAGR) ekspor kopi tahun 2014-2018 sebesar 2,1\%. Hal ini menunjukkan bahwa kenaikan ekspor kopi di Indonesia dikarenakan jumlah konsumsi kopi di dunia yang semakin meningkat.

Konsumsi kopi tidak hanya diminati oleh negara eropa saja, tetapi di Indonesia jumlah konsumsi kopi selalu meningkat tiap tahunnya. Meningkatnya budaya konsumsi minum kopi di Indonesia mendatangkan produk dan kedai-kedai kopi disekitar masyarakat. Produsen akan memperoleh keuntungan dari konsumen yang menikmati serta mengunjungi kedai kopi. Banyak konsumen yang mengunjungi kedai kopi tidak hanya untuk menikmati sajian minuman kopi saja, tetapi juga untuk menunjukkan status sosial.

Tabel 2. Jumlah Kedai Kopi di Kabupaten Karanganyar

\begin{tabular}{llc}
\hline No & \multicolumn{1}{c}{ Nama Kedai Kopi } & Peringkat \\
\hline 1. & Banaran 9 Coffee and Tea, Colomadu & $\mathbf{6 , 1}$ \\
2. & Sakaw Coffee and Bites & 5,7 \\
3. & Kedai Kopi Kapal Api & 4,7 \\
4. & Ngawe Kadang Kopi & 4,5 \\
5. & Bagong Coffee and Resto & 4,4 \\
6. & Dof Coffee Shop & 4,4 \\
7. & Coralian Coffee Shop & 4,3 \\
\hline
\end{tabular}

\section{Sumber : Foursquare, 2018}

Berdasarkan Tabel 2, menurut Foursquare yang merupakan sebuah situs web jejaring sosial berbasis lokasi yang bergantung pada software atau perangkat lunak dapat diketahui bahwa terdapat 7 kedai kopi yang tersebar di Kabupaten Karanganyar. Banaran 9 Coffee and Tea, Colomadu memiliki peringkat 6,1 dalam situs tersebut. Hal tersebut menandakan bahwa Banaran 9 Coffee and Tea, Colomadu sudah banyak dikenal oleh masyarakat dibandingkan dengan kedai kopi-kedai kopi lainnya yang ada di Kabupaten 
ISSN : 2622-6154 (print)

Karanganyar. Tradisi minum kopi tidak hanya sekadar untuk menikmati rasa minuman kopi, tetapi juga untuk menemani aktivitas kehidupan masyarakat seperti rapat, pertemuan bisnis, reuni, kencan, dan lain-lain. Hal inilah yang membuat tren meminum kopi terus meningkat dan tradisi minum kopi telah menjadi bagian dari gaya hidup (Suisa et al, 2014).

Budaya minum kopi saat ini merupakan suatu trend baru yang muncul diberbagai kalangan masyarakat. Meningkatnya permintaan akan kopi, mendorong munculnya berbagai brand, cafe, dan coffee shop di kota-kota besar (Kurniawan et al,2017). Persaingan bisnis kedai kopi di Kabupaten Karanganyar semakin ketat dikarenakan telah berdiri beberapa kedai kopi yang menyajikan tidak hanya produk minuman kopi saja, tetapi juga terdapat fasilitas lain. Menurut Herlyana (2012) kedai kopi menyediakan berbagai jenis kopi dan minuman non alkohol lainnya, tempat yang nyaman, dan dilengkapi dengan alunan musik, baik lewat pemutar lagu atau pun live music, menyediakan televisi, desain interior khas, pelayanan yang ramah, dan beberapa di antaranya menyedikan koneksi internet. Kopi kini telah menjadi bagian dari gaya hidup dengan banyaknya kedai kopi dan inovasi dalam pembuatan kopi, sehingga melahirkan semakin banyak penikmat kopi. Perlu adanya strategi pemasaran yang sesuai dengan target produsen untuk menghadapi persaingan bisnis kedai kopi di Karanganyar. Hal ini menjadikan produsen kedai kopi untuk memahami keinginan konsumen agar produk minuman kopi yang ditawarkan dapat diterima oleh masyarakat.

Pengambilan keputusan pembelian yang dilakukan oleh konsumen di Banaran 9 Coffee and Tea, Colomadu ini dipertimbangkan oleh beberapa faktor. Faktor-faktor yang di perhatikan berkaitan dengan faktor bauran pemasaran. Faktor bauran pemasaran ini meliputi produk, harga, tempat, promosi, orang, proses, dan sarana fisik atau seringkali di sebut dengan 7P (product, price, place and promotion, people, process and physical evidence). Bauran pemasaran sebagai bauran variabel pemasaran yang digunakan oleh perusahaan untuk mengejar penjualan yang diharapkan di pasar sasaran (Kotler dalam Rahayu et al,2015). Bagi produsen penting untuk mengetahui faktor-faktor yang dipertimbangkan konsumen dalam melakukan pembelian minuman kopi di Banaran 9 Coffee and Tea, Colomadu agar produsen dapat memahami kebutuhan dan keinginan konsumen melalui strategi bauran pemasaran 7P. Hal inilah yang mendorong peneliti mengadakan penelitian mengenai analisis faktor bauran pemasaran terhadap keputusan pembelian minuman kopi (Kasus pada Banaran 9 Coffee and Tea Colomadu, Kabupaten Karanganyar).

\section{METODE PENELITIAN}

Metode dasar yang digunakan dalam penelitian ini adalah metode deskriptif dan analitis. Penentuan lokasi dilakukan secara purposive yaitu Banaran 9 Coffee and Tea, Colomadu, Kabupaten Karanganyar. Metode pengambilan sampel yang digunakan dalam penelitian ini adalah Purposive Sampling. Jumlah sampel yang digunakan menurut Malhotra (2004), bahwa besarnya jumlah sampel yang diambil dapat ditentukan dengan cara mengalikan jumlah variabel dengan 5 , atau $5 \mathrm{X}$ jumlah variabel. Penelitian ini ada 22 variabel, jadi jumlah sampel yang dianggap mewakili dan mencerminkan ciri populasi 
ISSN : 2622-6154 (print)

adalah 110 orang. Penelitian ini menggunakan data primer dan data sekunder serta teknik pengambilan data dengan observasi, wawancara, pencatatan, dan dokumentasi.

\section{Metode Analisis Data}

\section{Transformasi Data}

Transformasi data dilakukan menggunakan MSI (Method of Succesive Interval) dengan mengubah data ordinal menjadi data interval (Heryanto dan Totok, 2018). Secara konseptual data yang telah didapatkan dari penyebaran kuisioner kepada responden dan selanjutnya dibuat dalam bentuk tabulasi merupakan data berskala ordinal yang akan diolah menjadi data berskala interval.

\section{Uji Validitas}

Validitas digunakan untuk mengetahui kelayakan pertanyaan dalam mendefinisikan suatu variabel. Pengujian validitas dilakukan dengan metode korelasi pearson correltion ( $\mathrm{r}$ hitung) $>\mathrm{r}$ tabel, yang menyatakan korelasi antara skor pertanyaan dengan skor total (item total correlation). Apabila koefisien korelasi yang diperoleh $>0,30$ maka dapat dikatakan item tersebut valid dengan uji validitas sampel yang digunakan minimal 30 responden (Azwar, 2009).

\section{Uji Reliabilitas}

Uji reliabilitas dilakukan dengan melihat koefisien alpha cronbach $(\alpha)$. Suatu instrumen dikatakan reliabel apabila koefisien alpha cronbach $(\alpha)$ lebih besar dari 0,7 (Widoyoko, 2012).

\section{Analisis Faktor}

Analisis faktor bauran pemasaran yang dipertimbangkan konsumen dalam melakukan pembelian minuman kopi di Banaran 9 Coffee and Tea. Secara matematis, model dari analisis faktor sebagai berikut:

$$
\begin{aligned}
F t= & b_{1} X_{1}+b_{2} X_{2}+b_{3} X_{3}+b_{4} X_{4}+b_{5} X_{5}+b_{6} X_{6}+b_{7} X_{7}+b_{8} X_{8}+b_{9} X_{9}+b_{10} X_{10}+b_{11} X_{11}+ \\
& b_{12} X_{12}+b_{13} X_{13}+b_{14} X_{14}+b_{15} X_{15}+b_{16} X_{16}+b_{17} X_{17}+b_{18} X_{18}+b_{19} X_{19}+b_{20} X_{20}+ \\
& b_{21} X_{21}+b_{22} X_{22}+e
\end{aligned}
$$

Keterangan :

Ft : Skor faktor bauran pemasaran minuman kopi di Banaran 9 Coffee and Tea, Colomadu yang terbentuk

$\mathrm{B}_{1}-\mathrm{B}_{23}$ : Koefisien skor faktor bauran pemasaran minuman kopi di Banaran 9 Coffee and Tea, Colomadu

$\mathrm{X}_{1}-\mathrm{X}_{22}$ : $\left(\mathrm{X}_{1}\right)$ Rasa, $\left(\mathrm{X}_{2}\right)$ Varian menu, $\left(\mathrm{X}_{3}\right)$ Kualitas, $\left(\mathrm{X}_{4}\right)$ Aroma kopi, $\left(\mathrm{X}_{5}\right)$ Keterjangkauan harga, $\left(\mathrm{X}_{6}\right)$ Kesesuaian harga, $\left(\mathrm{X}_{7}\right)$ Daya saing, $\left(\mathrm{X}_{8}\right)$ Iklan, $\left(\mathrm{X}_{9}\right)$ Pemberian hadiah, $\left(\mathrm{X}_{10}\right)$ Informasi dari mulut ke mulut, $\left(\mathrm{X}_{11}\right)$ Lokasi penjualan, $\left(\mathrm{X}_{12}\right)$ Aksesibilitas, $\left(\mathrm{X}_{13}\right)$ Lahan parkir, $\left(\mathrm{X}_{14}\right)$ Suasana tempat, $\left(\mathrm{X}_{15}\right)$ Desain tempat, $\left(\mathrm{X}_{16}\right)$ Fasilitas, $\left(\mathrm{X}_{17}\right)$ Proses pembuatan minuman kopi, $\left(\mathrm{X}_{18}\right)$ Kecepatan pelayanan, $\left(\mathrm{X}_{19}\right)$ Proses pembayaran, $\left(\mathrm{X}_{20}\right)$ Pelayanan pramusaji, $\left(\mathrm{X}_{21}\right)$ Penampilan pramusaji, $\left(\mathrm{X}_{22}\right)$ Penjelasan pramusaji.

E : Error

\section{HASIL DAN PEMBAHASAN}




\section{Kondisi Umum Banaran 9 Coffee and Tea Colomadu}

Kedai Banaran 9 Coffee and Tea Colomadu adalah salah satu cabang dari kedai Banaran 9 Coffee and Tea yang beralamat di Jalan Adi Sucipto Colomadu, Karanganyar yang telah berdiri pada 26 Agustus 2009. Banaran 9 Coffee and Tea merupakan kedai dibawah naungan perusahaan PTPN IX yang memproduksi kopi di daerah Bawen dan teh di daerah Kaligua. Kedai ini tidak hanya di Colomadu, Kedai Banaran 9 Coffe and Tea telah tersebar diberbagai kota di Jawa Tengah yaitu di Kota Semarang, Cilacap, dan Ambarawa. Berada di bagian barat komplek EX Pabrik Gula (PG) Colomadu yang sekarang telah di ubah menjadi kawasan wisata De Tjolomadoe. Kedai yang dibuka setiap hari pukul 09.00-23.00 WIB ini selalu ramai pengunjung dari kalangan pebisnis, keluarga, atau hanya sekadar berkumpul dengan teman. Produk menu minuman dan makanan yang beranekaragam sehingga dapat diterima oleh semua kalangan usia.

\section{Karakteristik Responden Banaran 9 Coffee and Tea Colomadu}

Tabel 3. Karakteristik Responden Banaran 9 Coffee and Tea Colomadu

\begin{tabular}{rllcc}
\hline No & Karakteristik & Keterangan & Frekuensi & Presentase \\
\hline 1 & Jenis Kelamin & Laki-laki & 76 & $69 \%$ \\
& & Perempuan & 34 & $31 \%$ \\
\hline 2 & Usia & $25-35$ & 39 & $35 \%$ \\
& & $35-45$ & 48 & $44 \%$ \\
& & $45-55$ & 23 & $21 \%$ \\
\hline 3 & Pendidikan & SMA & 12 & $11 \%$ \\
& & Diploma & 22 & $20 \%$ \\
& & S1 & 57 & $52 \%$ \\
\hline 4 & Pekerjaan & S2 & 19 & $17 \%$ \\
& & Pegawai Negeri & 14 & $13 \%$ \\
& & Pegawai Swasta & 37 & $34 \%$ \\
& & Wiraswasta & 55 & $50 \%$ \\
& & Tentara & 1 & $1 \%$ \\
\hline 5 & Pengeluaran Konsumen & Polisi & 1 & $1 \%$ \\
& & Ibu Rumah Tangga & 2 & $2 \%$ \\
& & Rp $\leq 3.000 .000$ & 9 & $8 \%$ \\
& & Rp 3.000.000<- $\leq \mathrm{Rp}$ & 62 & $56 \%$ \\
\hline
\end{tabular}

\section{Sumber: Analisis Data Primer, 2019}

Berdasarkan tabel 3, dapat diketahui bahwa sebagian besar konsumen yang melakukan keputusan pembelian produk minuman kopi Banaran 9 Coffee and tea adalah konsumen laki-laki yaitu sebesar 69\%. Sedangkan jumlah konsumen perempuan yang melakukan keputusan pembelian produk minuman kopi sebesar 31\%. Hal ini menandakan bahwa konsumen laki-laki lebih mendominasi dalam keputusan pembelian minuman kopi. Usia responden diketahui bahwa mayoritas konsumen dalam melakukan keputusan pembelian produk minuman kopi di Banaran 9 Coffee and Tea Colomadu adalah orang dengan kelompok umur 36-45 tahun yaitu sebesar 44\%. Menurut 
ISSN : 2622-6154 (print)

Suprayitno, et al (2015) usia konsumen dewasa merupakan usia produktif yang memiliki tingkat keputusan dengan baik. Presentase konsumen yang memiliki tingkat pendidikan terakhir S1 yaitu sebesar 52\%. Hal ini menunjukkan bahwa tingkat pendidikan akan memengaruhi keputusan pembelian minuman kopi. Mayoritas konsumen dalam melakukan keputusan pembelian minuman kopi di Banaran 9 Coffee and Tea Colomadu adalah wiraswasta dengan jumlah 55 responden dan presentase sebesar 50\% serta pada tingkat pengeluaran konsumen dalam sebulan, mayoritas konsumen memiliki pengeluaran antara 3.000.000<- $\geq 5.000 .000$ dengan presentase sebesar 56\%.

\section{Informasi Responden Mengenai Pengenalan Produk}

Tabel 4. Informasi Responden Banaran 9 Coffee and Tea Colomadu

\begin{tabular}{|c|c|c|c|c|}
\hline No & Informasi Konsumen & Keterangan & Frekuensi & Presentase \\
\hline \multirow[t]{5}{*}{1} & Lama Waktu Mengetahui & $\leq 3$ bulan & 8 & $7 \%$ \\
\hline & & 4-6 bulan & 7 & $6 \%$ \\
\hline & & $7-9$ bulan & 11 & $10 \%$ \\
\hline & & 10-12 bulan & 15 & $14 \%$ \\
\hline & & $\geq 12$ bulan & 69 & $63 \%$ \\
\hline \multirow[t]{3}{*}{2} & Sumber Informasi & Teman & 96 & $87 \%$ \\
\hline & & Media Sosial & 10 & $9 \%$ \\
\hline & & Lainnya & 4 & $4 \%$ \\
\hline \multirow[t]{5}{*}{3} & Alasan Melakukan Pembelian & Kumpul Keluarga & 17 & $16 \%$ \\
\hline & & Kumpul Teman & 28 & $25 \%$ \\
\hline & & Liburan & 21 & $19 \%$ \\
\hline & & Rapat & 39 & $36 \%$ \\
\hline & & Lainnya & 5 & $4 \%$ \\
\hline \multirow[t]{4}{*}{4} & Banyaknya Kali Pembelian & 2 kali & 27 & $25 \%$ \\
\hline & & 3 kali & 24 & $22 \%$ \\
\hline & & 4 kali & 20 & $18 \%$ \\
\hline & & $\geq 4$ kali & 39 & $35 \%$ \\
\hline
\end{tabular}

\section{Sumber: Analisis Data Primer, 2019}

Berdasarkan tabel 4, dapat diketahui bahwa keberadaan Banaran 9 Coffee and Tea telah lama diketahui oleh masyarakat dengan presentase $63 \%$. Hal tersebut membuktikan bahwa Banaran 9 Coffee and Tea Colomadu memiliki eksistensi yang baik di kalangan masyarakat. Sumber informasi yang diperoleh dari responden sebagian besar mengetahui keberadaan Banaran 9 Coffee and Tea melalui teman yaitu sebesar 87\%. Menurut Antinah (2010), informasi dari mulut ke mulut dapat terjadi dengan sendirinya, selain itu komunikasi dari mulut ke mulut juga lebih meyakinkan karena biasanya dasar seorang konsumen untuk mengkonsumsi kembali suatu jasa didasarkan pada pengalaman konsumen sebelumnya yang telah menggunakan jasa tersebut. Alasan responden melakukan keputusan pembelian menunjukkan bahwa sebagian besar konsumen melakukan keputusan pembelian minuman kopi di Banaran 9 Coffee and Tea Colomadu adalah kepentingan rapat sebesar $36 \%$. Banyaknya kali pembelian menunjukkan bahwa 
ISSN : 2622-6154 (print)

sebagian besar konsumen Banaran 9 Coffee and Tea, Colomadu merupakan pelanggan yang setia sebesar 35\% telah melakukan keputusan pembelian lebih dari 4 kali. Menurut Lovelock et al (2011) loyalitas konsumen merupakan sikap konsumen yang menggunakan produk produsen dalam jangka panjang, melakukan pembelian ulang dan merekomendasikan produk-produk produsen kepada teman

Analisis Faktor Menggunakan KMO (Kaiser Mayer Olkin)

Tabel 5. Uji KMO

\begin{tabular}{llr}
\hline Kaiser-Meyer-Olkin Measure of Sampling Adequacy. &, 717 \\
\hline Bartlett's Test of Sphericity & Approx. Chi-Square & 1014,680 \\
& Df & 231 \\
& Sig. &, 000 \\
\hline
\end{tabular}

\section{Sumber: Analisis Data Primer, 2019}

Berdasarkan tabel 5, hasil pengujian menunjukkan KMO (Kaiser Mayer Olkin) $0,717 \geq 0,5$. Hasil tersebut membuktikan bahwa semua variabel dapat dianalisis lebih lanjut. Selanjutnya untuk hasil Bartlett's Test Of Sphericity menunjukkan signifikansi $0,000<0,05$. Hasil tersebut membuktikan bahwa terdapat korelasi antar variabel.

Pengujian Anti Image Correlation Masing-masing variabel yang diseleksi tidak ada variabel dengan nilai MSA kurang dari 0,5. Hal ini menunjukkan tidak perlu mengekstraksi dan memilih variabel serta pengujian dapat dilanjutkan. Nilai communalities hasil pengujian masing-masing variabel memiliki nilai communalities diatas 0,5. Variabel tertinggi dapat dilihat pada variabel X1(rasa) dengan nilai extration 0,883 . Hal ini diartikan sebesar 88,3\% varian dari variabel rasa dapat dijelaskan oleh faktor terbentuk. Variabel terkecil yaitu variabel X8 (Iklan) dengan nilai extration 0,594. Hal ini diartikan sebesar 59,4\% variabel dapat dijelaskan oleh faktor yang terbentuk.

Nilai eigenvalue menunjukkan masing-masing faktor dalam menghitung variance semua variabel yang dianalisis memiliki kepentingan yang relatif. Total variance explained pada tabel diatas menghasilkan tujuh faktor yang dibentuk berdasarkan nilai eigenvalue lebih dari satu. Faktor pertama memiliki nilai eigenvalue sebesar 5,289; faktor kedua memiliki nilai eigenvalue sebesar 2,312; faktor ketiga memiliki nilai eigenvalue sebesar 2,181; faktor keempat memiliki nilai eigenvalue sebesar 1,946; faktor kelima memiliki nilai eigenvalue sebesar 1,447; faktor keenam memiliki nilai eigenvalue sebesar 1,081; Faktor-faktor yang terbentuk memiliki nilai total percentage of variance sebesar $70,613 \%$ dari 22 variabel yang dapat dijelaskan oleh tujuh faktor terbentuk. 
ISSN : 2622-6154 (print)

Tabel 6. Rotated Component Matrix

\begin{tabular}{|c|c|c|c|c|c|c|c|}
\hline & \multicolumn{7}{|c|}{ Component } \\
\hline & 1 & 2 & 3 & 4 & 5 & 6 & 7 \\
\hline X1 (Rasa) & ,929 & ,013 & ,027 & ,088 & ,033 & ,023 & ,095 \\
\hline X2 (Kualitas) & ,848 &, 124 & 070 & , 199 & , 105 & 064 & 093 \\
\hline X3 (Varian menu) & ,778 & $\begin{array}{r}- \\
, 017\end{array}$ & , 187 &,- 050 &,- 050 & ,203 & ,074 \\
\hline X4 (Aroma Kopi) & ,702 &, 121 & ,026 & ,381 &, 126 & ,023 & ,001 \\
\hline X5 ( Harga Terjangkau) &, 105 & ,074 &,- 126 &, 051 & ,219 & , 100 &, 846 \\
\hline X6 (Kesesuaian Harga) & ,096 &, 052 &,- 008 &,- 019 &, 171 & 059 & ,771 \\
\hline X7 ( Daya Saing Harga) & 030 &,- 005 & ,087 & , 440 &,- 182 &,- 033 & ,641 \\
\hline X8 (Iklan) & ,040 & ,840 &,- 018 & , 108 &,- 056 &, 060 &,- 035 \\
\hline X9 (Pemberian Hadiah) & ,138 & ,796 &, 213 & ,091 & ,028 & , 120 & ,088 \\
\hline $\begin{array}{l}\text { X10 (Informasi dari Mulut } \\
\text { ke Mulut) }\end{array}$ & 011 & ,864 & ,016 &,- 020 &,- 071 &, 065 & ,076 \\
\hline X11( Lokasi Penjualan) &,- 056 &,- 111 & ,194 & ,304 &,- 004 & ,779 & ,062 \\
\hline X12 (Asesibilitas) & 245 &, 133 &, 111 & , 122 &,- 013 & ,763 &,- 011 \\
\hline X13 (Lahan Parkir) & ,104 & ,273 & ,076 &,- 074 &, 151 & ,756 & ,119 \\
\hline X14 (Desain Tempat) &, 021 &,- 095 &, 250 &, 042 & ,716 &, 015 & 084 \\
\hline X15 ( Suasana Tempat) &, 082 &,- 056 &, 070 & ,302 &, 747 &,- 052 &,- 030 \\
\hline X16 (Fasilitas) & 039 &, 027 &, 028 &, 060 & ,731 &, 136 & ,239 \\
\hline X17 (Ketrampilan &, 024 &, 020 & ,860 &,- 003 &, 058 &, 118 &,- 032 \\
\hline Melayani Konsumen) & & & & & & & \\
\hline $\begin{array}{l}\text { X18 (Proses Pembuatan } \\
\text { Minuman Kopi) }\end{array}$ & ,048 &, 058 & ,781 & , 107 &, 177 & ,219 &,- 182 \\
\hline X19 (Proses Pembayaran) &, 232 &, 135 & ,747 & , 106 &, 138 & ,026 & , 125 \\
\hline $\begin{array}{l}\text { X20 (Pelayanan } \\
\text { Pramusaji) }\end{array}$ & ,067 & ,095 & 012 & ,785 & 055 & ,137 & , 192 \\
\hline $\begin{array}{l}\text { X21 (Penampilan } \\
\text { Pramusaji) }\end{array}$ &, 323 &, 087 & ,073 & ,644 & ,278 &, 127 &,- 023 \\
\hline $\begin{array}{l}\text { X22 ( Penjelasan } \\
\text { Pramusaji) }\end{array}$ & 274 &, 035 &, 177 & ,632 &, 371 &, 110 & ,027 \\
\hline
\end{tabular}

\section{Sumber: Analisis Data Primer, 2019}

Berdasarkan tabel 6, rotated component matrix menunjukkan distribusi 22 variabel telah di ektrak dalam faktor yang terbentuk bertujuan untuk mempertajam perbedaan factor loadingnya setelah dilakukan rotasi. Dalam penelitian ini menghasilkan tujuh faktor inti yang dapat mempengaruhi keputusan pembelian di Banaran 9 Coffee and Tea Colomadu. Faktor inti 1 terdiri dari empat variabel yaitu X1 (Rasa) memiliki nilai terhadap faktor inti sebesar 0,929; X2(Kualitas) 0,848; X3 (Varian menu) 0,778; X4 (Aroma Kopi) 0,702. Faktor inti 2 terdiri dari tiga variabel yaitu X10 (Informasi dari mulut ke mulut) 0,864; X9 (Pemberian hadiah) 0,796; X8 (Iklan) 0.840. Faktor inti 3 
terdiri dari tiga variabel yaitu X17 (Proses pembuatan minuman kopi) 0,860; X18 (Ketrampilan melayani konsumen) 0,781; X19 (Proses pembayaran) 0,747. Faktor inti 4 terdiri dari tiga variabel yaitu X20 (Pelayanan pramusaji) 0,785; X22 (Penjelasan pramusaji) 0,632; X21 (Penampilan pramusaji) 0,644.

Faktor selanjutnya inti 5 terdiri dari tiga variabel yaitu X15 (Suasana tempat) memiliki nilai terhadap faktor inti sebesar 0,747; X16 (Fasilitas) 0,731; X14 (Desain tempat) 0,716. Faktor inti 6 terdiri dari tiga variabel yaitu X11 (Lokasi penjualan) 0,779; X12 (Aksesibilitas) 0,763; X13 (Lahan Parkir) 0,756. Faktor terakhir yaitu inti 7 terdiri dari tiga variabel X5 (Harga terjangkau) 0,846; X6 (Kesesuaian harga) 0,771; X7 (Daya saing harga) 0,641 . Ketujuh faktor inti yang telah dijelaskan merupakan faktor baru yang terbentuk dari hasil analisis faktor yang telah di analisis.

\section{Hasil Analisis Faktor}

Tabel 7. Hasil Analisis Faktor

\begin{tabular}{|c|c|c|c|c|c|c|}
\hline Faktor & $\begin{array}{l}\text { Nama } \\
\text { Faktor }\end{array}$ & $\begin{array}{l}\% \text { of } \\
\text { Var }\end{array}$ & $\begin{array}{l}\text { Cumulative } \\
\text { Total Var } \\
(\%)\end{array}$ & Variabel & $\begin{array}{l}\text { Factor } \\
\text { Loading }\end{array}$ & $\begin{array}{l}\text { Eigen } \\
\text { Value }\end{array}$ \\
\hline 1 & Produk & 24,042 & 24,042 & $\begin{array}{l}\text { Rasa } \\
\text { Kualitas } \\
\text { Varian menu } \\
\text { Aroma Kopi }\end{array}$ & $\begin{array}{l}0,929 \\
0,848 \\
0,778 \\
0,702\end{array}$ & 5,289 \\
\hline 2 & Promosi & 10,507 & 34,549 & $\begin{array}{l}\text { Informasi mulut ke } \\
\text { mulut } \\
\text { Pemberian hadiah } \\
\text { Iklan }\end{array}$ & $\begin{array}{l}0,864 \\
0,840 \\
0,796\end{array}$ & 2,312 \\
\hline 3 & Proses & 9,913 & 44,462 & $\begin{array}{l}\text { Ketrampilan Pelayanan } \\
\text { Proses Pembuatan } \\
\text { Minuman Kopi } \\
\text { Proses Pembayaran }\end{array}$ & $\begin{array}{l}0,860 \\
0,781 \\
0,747\end{array}$ & 2,181 \\
\hline 4 & Orang & 8,845 & 53,307 & $\begin{array}{l}\text { Pelayanan Pramusaji } \\
\text { Penjelasan Pramusaji } \\
\text { Penampilan Pramusaji }\end{array}$ & $\begin{array}{l}0,785 \\
0,644 \\
0,632\end{array}$ & 1,946 \\
\hline 5 & $\begin{array}{l}\text { Bukti } \\
\text { Fisik }\end{array}$ & 6,576 & 59,882 & $\begin{array}{l}\text { Suasana Tempat } \\
\text { Fasilitas } \\
\text { Desain Tempat }\end{array}$ & $\begin{array}{l}0,747 \\
0,731 \\
0,716\end{array}$ & 1,447 \\
\hline 6 & Tempat & 5,815 & 65,698 & $\begin{array}{l}\text { Lokasi Penjualan } \\
\text { Aksesibilitas } \\
\text { Lahan Parkir }\end{array}$ & $\begin{array}{l}0,779 \\
0,763 \\
0,756\end{array}$ & 1,279 \\
\hline 7 & Harga & 4,916 & 70,613 & $\begin{array}{l}\text { Harga Terjangkau } \\
\text { Kesesuaian Harga } \\
\text { Daya Saing Harga }\end{array}$ & $\begin{array}{l}0,846 \\
0,771 \\
0,641\end{array}$ & 1,081 \\
\hline
\end{tabular}

\section{Sumber: Analisis Data Primer, 2019}

Berdasarkan tabel 7, menunjukkan hasil analisis faktor menggunakan 22 variabel dan tercakup dalam tujuh faktor inti dengan persentase total varian sebesar 70,613\%. Hal ini membuktikan bahwa penelitian ini mampu menjelaskan faktor-faktor yangdipertimbangkan dalam keputusan pembelian di Banaran 9 Coffee and Tea 
ISSN : 2622-6154 (print)

Colomadu sebesar 70,613\%. Sedangkan sisanya sebesar 29,387\% dijelaskan oleh faktor lain yang tidak tercakup dalam analisis faktor. 7 faktor inti yang terbentuk berdasarkan prioritasnya adalah sebagai berikut: a). Faktor 1 (Produk) merupakan faktor pertama yang dipertimbangkan konsumen dalam keputusan pembelian di Banaran 9 Coffee and Tea Colomadu dengan persentase varians sebesar 24,042\%. Variabel-variabel yang tercakup dalam faktor produk adalah variabel rasa, kualitas, varian menu, aroma kopi. Berdasarkan nilai factor loading, variabel rasa merupakan variabel yang paling dipertimbangkan dalam faktor produk yaitu sebesar 0,929\%. b) Faktor 2 (Promosi) merupakan faktor kedua yang dipertimbangkan konsumen dalam keputusan pembelian di Banaran 9 Coffee and Tea Colomadu dengan persentase varian sebesar 34,549\%. Variabel-variabel yang tercakup dalam faktor promosi adalah informasi dari mulut ke mulut, pemberian hadiah, iklan. Berdasarkan nilai factor loading, variabel informasi dari mulut ke mulut merupakan variabel yang paling dipertimbangkan dalam faktor promosi yaitu sebesar 0,864\%. c) Faktor 3 (Proses) merupakan faktor ketiga yang dipertimbangkan konsumen dalam keputusan pembelian di Banaran 9 Coffee and Tea Colomadu dengan persentase varian sebesar $44,462 \%$. Variabel-variabel yang tercakup dalam faktor proses adalah informasi dari ketrampilan melayani konsumen, proses pembuatan minuman kopi, dan proses pembayaran. Berdasarkan nilai factor loading, variabel ketrampilan melayani konsumen merupakan variabel yang paling dipertimbangkan dalam faktor proses yaitu sebesar $0,860 \%$. d) Faktor 4 (Orang) merupakan faktor keempat yang dipertimbangkan konsumen dalam keputusan pembelian di Banaran 9 Coffee and Tea Colomadu dengan persentase varian sebesar 53,307\%. Variabel-variabel yang tercakup dalam faktor orang adalah pelayanan pramusaji, penjelasan pramusaji, dan penampilan pramusaji. Berdasarkan nilai factor loading, variabel pelayanan pramusaji merupakan variabel yang paling dipertimbangkan dalam faktor orang yaitu sebesar 0,785\%. e) Faktor 5 (Bukti fisik) merupakan faktor kelima yang dipertimbangkan konsumen dalam keputusan pembelian di Banaran 9 Coffee and Tea Colomadu dengan persentase varian sebesar $59,882 \%$. Variabel-variabel yang tercakup dalam faktor bukti fisik adalah suasana tempat, fasilitas, dan desain tempat. Berdasarkan nilai factor loading, variabel suasana tempat merupakan variabel yang paling dipertimbangkan dalam faktor bukti fisik yaitu sebesar $0,747 \%$. f) Faktor 6 (Tempat) merupakan faktor keenam yang dipertimbangkan konsumen dalam keputusan pembelian di Banaran 9 Coffee and Tea Colomadu dengan persentase varian sebesar $65.698 \%$. Variabel-variabel yang tercakup dalam faktor tempat adalah lokasi penjualan, aksesibilitas, dan lahan parkir. Berdasarkan nilai factor loading, variabel lokasi penjualan merupakan variabel yang paling dipertimbangkan dalam faktor tempat yaitu sebesar 0,779\%. g) Faktor 7 (Harga) merupakan faktor ketujuh yang dipertimbangkan konsumen dalam keputusan pembelian di Banaran 9 Coffee and Tea Colomadu dengan persentase varian sebesar $70.613 \%$. Variabel-variabel yang tercakup dalam faktor harga adalah harga terjangkau, kesesuaian harga, dan daya saing harga. Berdasarkan nilai factor loading, variabel harga terjangkau merupakan variabel yang paling dipertimbangkan dalam faktor harga yaitu sebesar $0,846 \%$.

\section{KESIMPULAN}


Analisis faktor bauran pemasaran yang dipertimbangkan konsumen dalam membeli minuman kopi di Banaran 9 Coffee and Tea Colomadu, Kabupaten Karanganyar menunjukkan bahwa dari 22 variabel dan tercakup dari 7 faktor inti. Faktor tersebut berdasarkan prioritasnya adalah faktor produk, faktor promosi, faktor proses, faktor orang, faktor bukti fisik, faktor tempat dan faktor harga. Variabel yang paling dipertimbangkan konsumen dalam keputusan pembelian minuman kopi di Banaran 9 Coffee and Tea, Colomadu berdasarkan nilai factor loading tertinggi. Variabel yang paling dipertimbangkan adalah variabel rasa.

\section{DAFTAR PUSTAKA}

Antinah. 2010. Komunikasi dari Mulut ke Mulut Pengaruhnya Terhadap Loyalitas Pelanggan pada Cipaganti Shuttle service Trayek Bandung: Jakarta Cabang Dipatiukur di PT. Cipaganti Citra Graha Bandung. [Skripsi]. Bandung: UNIKOM. Azwar, S. 2009. Penyusunan Skala Psikologi. Cetakan.9. Yogyakarta: Pustaka Pelajar.

Herlyana, E. 2012. Fenomena Coffee Shop Sebagai Gejala Gaya Hidup Kaum Muda. Thaqafiyyat.13(1).

Heryanto, I dan Totok. 2018. Path Analysis Menggunakan SPSS dan Execl. Bandung : Penerbit Informatika Bandung.

International Coffee Organization (ICO). 2017. Exports of Coffee by Exporting Countries. http://www.ico.org. Diakses pada 20 Oktober 2018

Kurniawan, A dan Muhammad, R. 2017. Perilaku Konsumtif Remaja Penikmat Warung Kopi. Jurnal Sosiologi DILEMA. 32(1).

Lovelock, et al. 2011. Pemasaran Jasa.edisi 7. Erlangga: Jakarta

Malhotra, N. 2004. Marketing Research and Applied Orientation Fourth Edition. USA: Prentice Hall International.

Praza, R. 2017. Dentifikasi Saluran Pemasaran Kopi Arabika Gayo pada CV.Gayo Mandiri Coffee Kabupaten Bener Meriah. Jurnal AGRIFO. 2(1).

Rahayu, et al. 2015. Marketing Mix Analysis Of Natural Tourism Area 'Kawah Putih' And Its Effect On Visitors' Decision. Indonesian Journal of Business and Entrepreneurship.1(2).

Suisa, K dan Febrilia, V. 2014. Gaya Hidup Minum Kopi Konsumen Di The Coffee Bean \& Tea Leaf Plasa Tunjungan Surabaya. Jurnal Hospitality dan Manajemen Jasa. 2(2).

Suprayitno, et al. 2015. Pengaruh Faktor Budaya, Sosial, Pribadi, dan Psikologi Konsumen terhadap Keputusan Pembelian pada Restoran Gado-Gado Boplo (Studi Kasus: Restoran Gado-Gado Boplo Panglima Polim Jakarta Selatan). Jurnal Agribisnis. 9(2).

Widoyoko. 2012. Teknik Penyusunan Instrumen Penelitian. Pustaka Pelajar: Yogyakarta. 